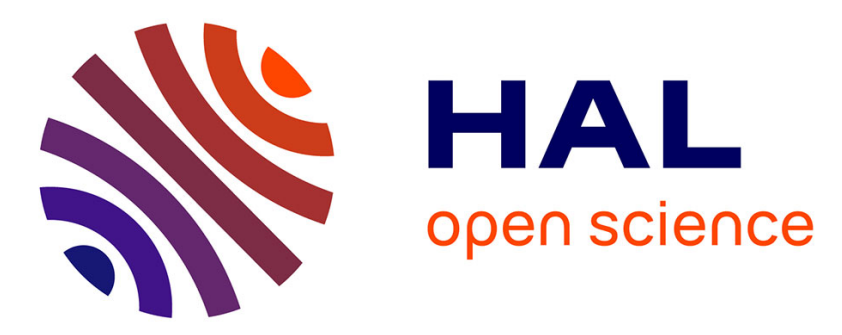

\title{
Measuring and understanding the most complex ultrashort pulse ever generated
}

\author{
R. Trebino, J.M. Dudley, Yuqiao Gu
}

\section{To cite this version:}

R. Trebino, J.M. Dudley, Yuqiao Gu. Measuring and understanding the most complex ultrashort pulse ever generated. Optics and photonics news, 2003, 14 (12), pp.44. 10.1364/OPN.14.12.000044 . hal-00094967

\section{HAL Id: hal-00094967 \\ https://hal.science/hal-00094967}

Submitted on 22 Apr 2021

HAL is a multi-disciplinary open access archive for the deposit and dissemination of scientific research documents, whether they are published or not. The documents may come from teaching and research institutions in France or abroad, or from public or private research centers.
L'archive ouverte pluridisciplinaire HAL, est destinée au dépôt et à la diffusion de documents scientifiques de niveau recherche, publiés ou non, émanant des établissements d'enseignement et de recherche français ou étrangers, des laboratoires publics ou privés. 
ULTRAFAST

\section{TECHNOLOGY}

\section{Measuring and Understanding the Most Complex Ultrashort Pulse Ever Generated}

Rick Trebino, bhn Dudley and Xun Gu

0 ne of the most exciting recent developments in optics has been the generation of ultrabroadband supercontinuum, accomplished simply by injecting readily available low-power ultrashort pulses into microstructure or tapered fibers. ${ }^{2-4}$ These new fibers are nearly dispersion free at the Ti:sapphire laser wavelength, so the pulse remains short for a much longer distance than in conventional fibers (for many centimeters compared with a few hundred micrometers), dramatically increasing nonlinear optical effects. The resulting continuum's spectrum encompasses the entire visible and much of the infrared ranges, and spatially it is also highly coherent. Many applications, in areas ranging from metrology to medical imaging, have been proposed and demonstrated for this exotic light, but detailed measurement and understanding of this most complex pulse ever generated have both eluded researchers. Indeed, the incredible complexity of the supercontinuum provides a particular challenge to both models and measurement techniques.

In this work, we combined powerful new modeling capabilities and new measurement techniques to accurately model and measure the continuum's complete intensity and phase vs. time, revealing several complete surprises and important new strategies for using this fiber in the future.

In our simulations, for example, we found, quite surprisingly, that the extreme spectral width is actually achieved in the first centimeter of fiber. Also surprisingly, the strong spectral broadening in the first centimeter is also accompanied by strong pulse temporal compression. With further propagation, the already broad spectrum develops only asymmetry and complex temporal features, such as temporal pulse break-up, oscillations and distinct soliton pulses, (a)

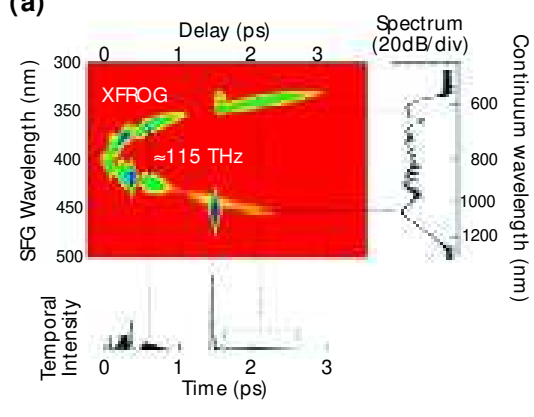

(b)

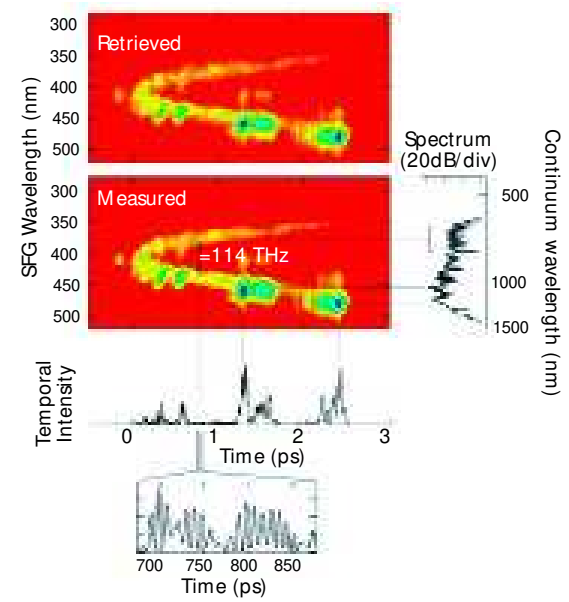

Figure 1. (a) Simulated supercontinuum spectrogram which shows the pulse break up and complex spectrum after propagating $16 \mathrm{~cm}$. (b) Measured and retrieved (a check on the measurement) continuum spectrograms showing the complex behavior predicted. In both cases, the intensity is shown below and the spectrum at right. (The original Optics Express paper contained a movie that showed the continuum spectrogram vs. distance along the fiber.)

which separate from the residual input pulse due to group velocity walk-off.

Also, because continuum contains such a broad spectrum that dispersion in the spectral wings becomes important, further propagation actually broaden s the continuum significantly in time, rather than frequency. All the latter features, which only occur for longer $(>1 \mathrm{~cm})$ fiber lengths, are generally undesirable.

Previous measurements of the continuum had been limited to simple multishot spectral measurements, which have always yielded a broad, smooth and stable spectrum. In contrast, we performed much more powerful cross-correlation frequency-resolved-optical-gating (XFROG) measurements with a newly developed angle-dithered-crystal technique to achieve the huge bandwidth necessary to measure continuum. These measurements generate a spectrogram of the continuum, which visually displays its time and frequency characteristics, as well as yielding the first complete intensity and phase measurement of the continuum. Our measurements revealed the continuum intensity and color vs. time and yielded some very surprising conclusions. First, in strong contrast to previous simple multi-shot spectrometer measurements, they showed a very complex and unstable spectrum, which was in good agreement both with our theory and also with single-shot spectral measurements we made to confirm these unintuitive results. Thus, we found that the contin- uum spectrum is broad, but neither smooth nor stable! Also, they showed that the continuum pulse generated in long (many centimeter) fibers is quite longseveral picoseconds-in agreement with our simulations.

The figure shows the theoretical and experimental continuum spectrograms, revealing the complex structure and the typical spectral oscillations that occur with a long $(16 \mathrm{~cm})$ fiber. The oscillation frequency varies across the profile, with a mean frequency of about $115 \mathrm{THz}$.

These simulations and measurements clearly showed that, while the input pulse can propagate large distances in these fibers without distortion, the continuum cannot. Thus, the optimal approach to supercontinuum generation is to use a short, $\sim 1 \mathrm{~cm}$, fiber. Indeed, using such a fiber, we have recently succeeded in generating a supercontinuum pulse only 25 fs long - considerably shorter than the 40 -fs pulse that created it - and also much smoother and much more stable. This short-fiber continuum is not only a nearly ideal pulse for most broadband applications, it is also potentially compressible to a few femtoseconds.

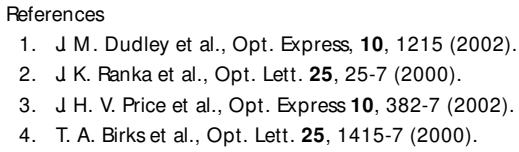

Rick Trebino (rick.trebino@physics.gatech.edu) and Xun Gu are with Georgia Institute of Technology, Atlanta, Ga. Jhn Dudley is with the Laboratoire d'Optique, France. 